\title{
Pseudoangiomatous Stromal Hyperplasia A rare mimic of breast malignancy
}

"Philips G. Michael, ${ }^{1}$ Tahra Al-Saadi, ${ }^{1}$ Rakesh Jamkhandikar, ${ }^{1}$ Lakshmi Rao ${ }^{2}$

$$
\text { فرط التنسج السدوي متعلق بشبه ورم وعائي }
$$

فيليبس جورج مايكل، طاهرة السعدي، راكث جامخاندركار، لاشكيمي راو
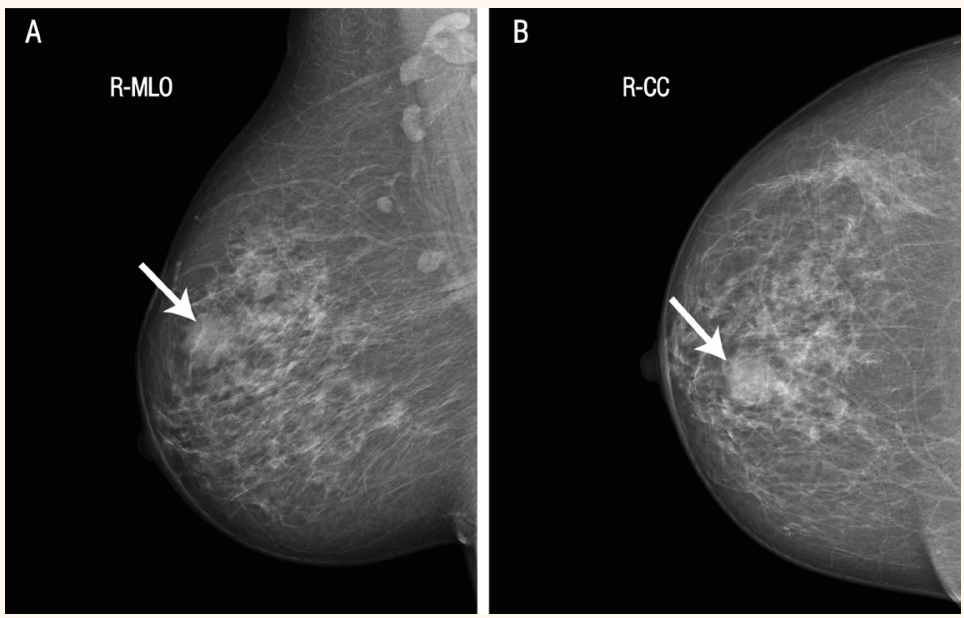

Figure 1: Mammography of the right breast of a 48-year-old premenopausal woman from the (A) mediolateral oblique and (B) craniocaudal views. A round mass with slightly lobulated margins can be observed (arrows).

$R=$ right breast; $M L O=$ mediolateral oblique; $C C=$ craniocaudal .

A 48-YEAR-OLD PREMENOPAUSAL WOMAN presented to the Breast Clinic of the Armed Forces Hospital, Muscat, Oman, in 2015 with a one-year history of a lump in her right breast which was progressively increasing in size. She had no associated fever or nipple discharge. The patient had three children whom she had breastfed normally. She was not lactating at the time of presentation and did not have a history of previous breast-related surgeries or trauma. On clinical examination, the right breast was found to be enlarged and diffusely erythematous with prominent superficial veins and skin changes. There was a palpable non-tender mass measuring approximately $1.5 \times 2.5 \mathrm{~cm}$ in size which was suspected to be malignant (i.e. an inflammatory carcinoma). The axillary lymph nodes were not palpable.

Mammography and ultrasonography of both breasts was performed. The mammogram revealed a lesion in the right breast which was rounded with slightly lobulated margins [Figure 1]. The lesion was classified as Breast Imaging-Reporting and Data System category 4. No microcalcifications were evident. The ultrasound scan showed a $1.5 \times 2.5 \mathrm{~cm}$ hypoechoic mass in the same location as that of the mammographic abnormality [Figure 2]. A colour Doppler ultrasound did not show any flow within the lesion. Radiologically, the appearance of the lesion was suggestive of a fibroadenoma or phyllodes tumour. However, due to concern that the lesion might be malignant, a histopathological examination was advised. Fine-needle aspiration cytology results were equivocal. Subsequently, an ultrasound-guided core biopsy of the lesion revealed the presence of spindle cells in a pseudoangiomatous pattern within the fibrous tissue [Figure 3]. This confirmed the diagnosis of pseudoangiomatous stromal hyperplasia (PASH). The lesion was surgically excised through a small incision with excellent postoperative cosmetic results. The patient was followed-up for two years without evidence of recurrence. 


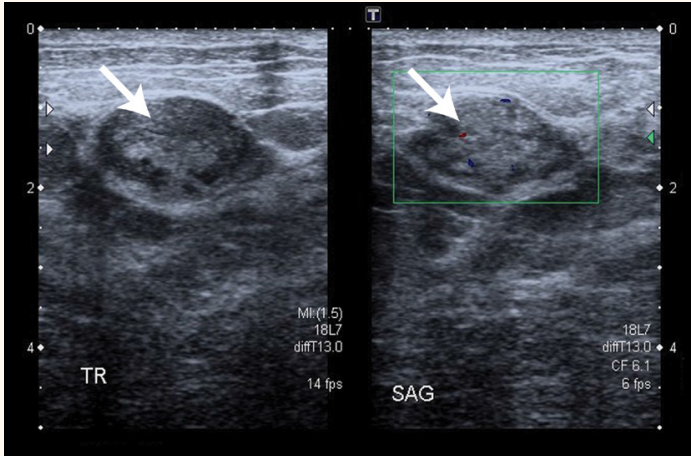

Figure 2: Ultrasonography of the right breast of a 48-year-old premenopausal woman from the (A) transverse and (B) sagittal aspects showing an avascular hypoechoic mass (arrows). This mass was in the same location as a clinically palpable lump and mammographic abnormality.

$T R=$ transverse $; A G=$ sagittal .

\section{Comment}

PASH refers to a rare benign mesenchymal proliferative lesion of the breast. $^{1}$ While the precise aetiology of this condition is not yet well understood, a hormonal cause has been proposed., ${ }^{1,2}$ This is supported by the fact that the majority of patients with PASH are premenopausal. ${ }^{2}$ In addition, the use of oral contraceptives and hormonal replacement therapy have been implicated. ${ }^{2,3}$ The current case is interesting for several reasons. First, the atypical clinical presentation of PASH in the patient initially indicated focal inflammatory or granulomatous mastitis or an inflammatory breast carcinoma. Second, the imaging findings primarily resembled a fibroadenoma or phyllodes tumour; however, the possibility of a malignant lesion could not be excluded. Third, a final histopathological diagnosis of PASH is extremely rare. ${ }^{3}$

A preoperative diagnosis of PASH based on fine-needle aspiration cytology is not possible since the results are non-specific; a core biopsy may help to establish the diagnosis, although in some cases a diagnosis can be made only after surgical excision. ${ }^{4}$ Histologically, PASH is composed of complex interanastomosing slit-like spaces within the breast parenchyma lined by spindle cells. The absence of blood cells within these structures and the lack of cellular atypia or mitotic activity can help to differentiate PASH from low-grade angiosarcomas. ${ }^{5}$ Differentiation between these two entities is vital due to differences in their management and prognosis. ${ }^{3-5}$ In equivocal cases, immunohistochemistry also plays a role in diagnosis since PASH lesions are positive for vimentin and cluster of differentiation (CD) 34 and negative for cytokeratins and factor VIIIrelated antigen.,

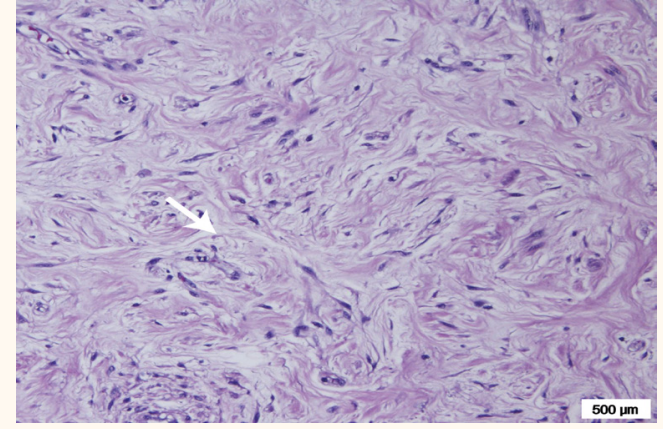

Figure 3: Haematoxylin and eosin stain of a core needle biopsy of a right breast lesion at x200 magnification showing the presence of spindle cells in a pseudoangiomatous pattern (arrow) within the fibrous tissue, in keeping with a diagnosis of pseudoangiomatous stromal hyperplasia.

Radiologically, PASH lesions have no pathognomonic or specific diagnostic features. These tumours commonly resemble fibroadenomas or hamartomas on imaging, although more serious pathologies such as angiosarcomas cannot be excluded. ${ }^{1,3,5}$ Large tumours may also be mistaken for phyllodes tumours. ${ }^{3-5}$ On mammography and ultrasonography, the lesion commonly appears as a well-defined mass or a hypoechoic discrete mass with benign features, respectively. ${ }^{4}$ However, case reports of lesions with irregular, illdefined or spiculated margins have been described, making it difficult to exclude the possibility of malignancy based on imaging alone. ${ }^{3-5}$ Several factors influence the management of PASH. For lesions that are small, asymptomatic and unequivocally confirmed by biopsy, surgical excision can be avoided; in contrast, surgery is indicated for larger lesions, for patients where the preoperative histology cannot confirm a diagnosis or in cases with suspicious clinical or radiological features. ${ }^{2-5}$

\section{References}

1. Masannat YA, Whitehead S, Hawley I, Apthorp L, Shah EF. Pseudoangiomatous stromal hyperplasia: A case report. Case Rep Med 2010; 2010:549643. doi: 10.1155/2010/549643.

2. Almohawes E, Khoumais N, Arafah M. Pseudoangiomatous stromal hyperplasia of the breast: A case report of a 12-yearold girl. Radiol Case Rep 2015; 10:1-4. doi: 10.1016/j. radcr.2015.06.007.

3. Kutlutürk K, Usta S, Ünal B, Karadağ N, Akatlı AN. Pseudoangiomatous stromal hyperplasia of the breast presenting as a giant breast tumor: A case report. J Breast Health (2013) 2015; 11:39-41. doi: 10.5152/tjbh.2014.1977.

4. Jones KN, Glazebrook KN, Reynolds C. Pseudoangiomatous stromal hyperplasia: Imaging findings with pathologic and clinical correlation. AJR Am J Roentgenol 2010; 195:1036-42. doi: 10.2214/AJR.09.3284.

5. Bowman E, Oprea G, Okoli J, Gundry K, Rizzo M, GabramMendola S, et al. Pseudoangiomatous stromal hyperplasia (PASH) of the breast: A series of 24 patients. Breast J 2012; 18:242-7. doi: 10.1111/j.1524-4741.2012.01230.x. 